\title{
Quantitative study on benefits of distribution network investment
}

\author{
He Yongxiu ${ }^{1}, \mathrm{Lu} \mathrm{Ye}^{1, \mathrm{a}^{*}}$ \\ ${ }^{1}$ School of Economics and Management, North China Electric Power University, Beijing 102206, China
}

\begin{abstract}
The development of distribution network in China lags behind the transmission network seriously, which is difficult to meet the development needs of high proportion of renewable energy power system in the future. Facing the huge investment demand of distribution network, it is urgent to improve the existing extensive experience based investment decision-making method and avoid the subjectivity of qualitative index evaluation method. In this paper, the life cycle theory and input-output method are used to study the quantification of distribution network investment benefit. The quantitative models of economic benefit and social benefit of distribution network investment are established to provide support for the comparison and decision-making of distribution network projects. Finally, an empirical analysis of the investment benefit model of a high-voltage distribution network project is carried out to verify the feasibility of the research results.
\end{abstract}

\section{Introduction}

With the goal of carbon peak and carbon neutral proposed, high proportion of renewable energy power system has become an inevitable development trend. In order to adapt to the flexible regulation and consumption of renewable energy, the investment scale of distribution network construction is increasing, and its investment benefit has also been focused on [1]. However, there is a lack of clear standards for the evaluation and comparison of distribution network projects, and there are many problems in the project arrangement, so it is necessary to conduct in-depth research on the quantification of distribution network investment benefit [2-3].

The current distribution network investment benefit evaluation relies more on experience and qualitative index scoring, and the analysis of investment benefit in relevant literature is lack of comprehensiveness and scientificity [4]. In order to comprehensively and intuitively reflect the investment benefits of distribution network projects, this paper uses the life cycle theory to build a quantitative model of economic and social benefits of distribution network investment in monetary terms, which provides support for the comparison and decision-making of distribution network projects.

\section{Quantitative model of distribution network investment benefit}

\section{1 construction of economic benefit model of distribution network investment}

Considering the life cycle cost and life cycle income of distribution network project [5-6], the investment economic benefit model is constructed, as shown in equation (1).

$$
B_{\text {eco }}=I_{\text {income }}-C_{\mathrm{LCC}}
$$

Where: ${ }_{\text {eco }}$ represents the economic benefit of the distribution network investment project, $I_{\text {income }}$ represents the life cycle income of the distribution network project, and $C_{\mathrm{LLC}}$ represents the life cycle cost of the distribution network project.

(1) Life cycle cost model of distribution network investment

The life cycle cost model of distribution network is constructed, as shown in equation (2). The cost of distribution network in investment phase, operation phase and retirement phase is calculated respectively, as shown in formula (3) (5).

$$
\begin{aligned}
& C_{\mathrm{LLC}}=C_{\text {invest }}+C_{\text {operation }}+C_{\text {retirement }} \\
& C_{\text {invest }}=C_{\text {purchase }}+C_{\text {installation }}+C_{\text {land }}+C_{\text {reserve }}+C_{\text {other }} \\
& C_{\text {operation }}=\sum_{t=1}^{\mathrm{T}}\left(\left(C_{\text {buy }}^{t}+C_{\text {main }}^{t}\right) \times(1+r)^{-t}\right) \\
& C_{\text {retirement }}=\left(C_{\text {dispose }}^{T}-C_{\text {residual }}^{T}\right) \times(1+r)^{-T}
\end{aligned}
$$

Where: $C_{\text {invest }}$ is the investment phase cost of the distribution network project, $C_{\text {operation }}$ is the operation phase cost of the distribution network project, $C_{\text {retirement }}$ is the retirement phase cost of the distribution network

\footnotetext{
${ }^{\text {a }}$ Corresponding author: luye1933@163.com
} 
project. $C_{\text {purchase }}$ is the equipment purchase cost, $C_{\text {installion }}$ is the construction cost, $C_{\text {land }}$ is the land cost, $C_{\text {reserve }}$ is the basic reserve cost, $C_{\text {other }}$ is other expenses in the investment phase, $C_{\text {buy }}^{t}$ is the power purchase cost of the distribution network project in each year, $C_{\text {main }}^{t}$ is the operation and maintenance cost of the distribution network project in each year, $r$ is the discount rate, $C_{\text {dispose }}^{T}$ is the decommissioning cost of the distribution

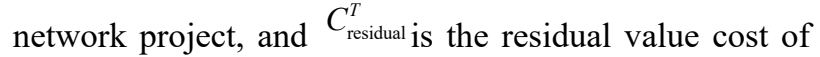
the equipment of the distribution network project.

(2) The life cycle income model of distribution network investment

The life cycle income of distribution network investment is the present value of the income from electricity sales in each year, as shown in formula (6). The revenue from sales for each year is the product of the electricity sold and the price of sale, as shown in formula (7).

$$
\begin{gathered}
I_{\text {income }}=\sum_{\mathrm{t}=1}^{\mathrm{T}}\left(I_{\mathrm{add}}^{\mathrm{t}} \times(1+r)^{-\mathrm{t}}\right) \\
I_{\mathrm{add}}^{t}=\sum_{i=1}^{4} \sum_{u=1}^{4}\left(q_{i, u}^{\mathrm{t}} \times p_{i, u} \times \lambda\right)
\end{gathered}
$$

Where: $I_{\text {add }}^{t}$ represents the increased power supply revenue of each year, ${ }^{t}{ }_{i, u}$ refers to the increased power supply of each year of the power supply unit where the distribution network project is located, and the value of $i$ is $1 \sim 4$, which represents the voltage levels of $1 \mathrm{kV}$ and below, $10 \mathrm{kV}, 35 \mathrm{kV}$ and $110 \mathrm{kV}$ respectively, and the value of $u$ is $1 \sim 4$, which represents the user categories of large industry, general industry and commerce, residents and agriculture respectively, $p_{i, u}$ is the sales price of different voltage levels and different user categories, $\lambda$ is the proportion of the original value of the fixed assets of the distribution network project in the total assets of the power supply unit.

\section{2 construction of social benefit model of distribution network investment}

The social benefits of distribution network include reliability benefits, environmental benefits, driving economic benefits, and photovoltaic poverty alleviation benefits [7-8], as shown in equation (8).

$$
B_{\text {social }}=\sum_{t=1}^{T}\left(B_{\text {reliable }}^{t}+B_{\text {envir }}^{t}+B_{\text {pull }}+B_{\mathrm{pv}}^{t}\right) \times(1+r)^{-t}
$$

Where: ${ }^{B_{\text {social }}}$ represents the social benefits of the distribution network project investment, $B_{\text {reliable }}^{t}$ represents the reliability benefits of each year, $B_{\text {envir }}^{t}$ represents the environmental benefits of each year, $B_{\text {pull }}$ represents the industry driven benefits of each year, and $B_{\mathrm{pv}}^{t}$ represents the photovoltaic poverty alleviation benefits of each year.

(1) Reliability benefit.

The construction investment of distribution network increases the reliability of power supply, thus reducing the loss of social benefits caused by power shortage. In this paper, the GDP per unit of electricity is used as the loss coefficient of social benefits to calculate the reliability benefits of distribution network project investment, as shown in formula (9).

$$
B_{\text {reliable }}^{t}=Q_{\text {total }} \times\left(R-R_{0}\right) \times P_{\mathrm{GDP}}
$$

Where: $Q_{\text {total }}$ represents the total power consumption of the distribution area, $R$ represents the power supply reliability rate of the distribution area after the project construction, $R_{0}$ represents the power supply reliability rate of the distribution area before the project construction, and $P_{\mathrm{GDP}}$ represents the Gross Regional Product generated by the unit power.

(2) Environmental benefits.

The distribution network project reduces environmental pollution through energy conservation and emission reduction, electric energy substitution, renewable energy interconnection and consumption. The resulting environmental benefits are the sum of the treatment costs of carbon dioxide, sulfur dioxide and nitrogen oxides, as shown in formula (10).

$$
B_{\text {envir }}^{t}=B_{\text {carbon }}^{t}+B_{\text {sulfur }}^{t}+B_{\text {nitric }}^{t}
$$

Where: $B_{\text {carbon }}^{t}$ represents the carbon dioxide emission reduction benefits in each year, $B_{\text {sulfur represents the sulfur }}^{t}$ dioxide emission reduction benefits in each year, and $B_{\text {nitric }}^{t}$ represents the nitrogen oxide emission reduction benefits in each year.

The emission of carbon dioxide, sulfur dioxide and nitrogen oxide reduced due to energy conservation and emission reduction is calculated by coal power unit, as shown in formula $(11) \sim(13)$.

$$
\begin{gathered}
B_{\text {carbon }}^{t}=Q_{\text {envir }} \times Q_{\text {carbon,coal }} \times C_{\text {carbon }} \\
B_{\text {sulfur }}^{t}=Q_{\text {envir }} \times Q_{\text {sulfur,coal }} \times C_{\text {sulfur }} \\
B_{\text {nitric }}^{t}=Q_{\text {envir }} \times Q_{\text {nitric,coal }} \times C_{\text {nitric }}
\end{gathered}
$$

Where: $Q_{\text {carbon,coal }}$ represents the carbon dioxide emission of unit thermal power generation, $Q_{\text {sulfur,coal }}$ represents the sulfur dioxide emission of unit thermal power generation, $Q_{\text {nitric,coal }}$ represents the nitrogen oxide emission of unit thermal power generation, $C_{\text {carbon }}$ represents the treatment cost of unit carbon dioxide, $C_{\text {sulfur }}$ represents the treatment cost of unit sulfur dioxide 
and $C_{\text {nitric }}$ represents the treatment cost of unit nitrogen oxide.

(3) To promote economic benefits. By using the decomposition coefficient of distribution network project investment in 42 national economic departments and the total consumption coefficient among each department, the pulling coefficient of the construction investment of distribution network project to each department can be calculated, expressed by matrix $\boldsymbol{B}_{n \times 1}$, as shown in formula (14).

$$
\boldsymbol{B}_{n \times 1}=\boldsymbol{S}_{n \times n} \times \boldsymbol{M}_{n \times 1}
$$

Where: $\boldsymbol{S}_{n \times n}$ represents the complete consumption coefficient matrix among departments, and $\boldsymbol{M}_{n \times 1}$ represents the decomposition matrix of $n$ department for the investment of distribution network project.

The pulling coefficient of the construction investment of distribution network project on each department is used to calculate the pulling effect of the investment of distribution network project on economy, as shown in formula (15).

$$
B_{\text {pull }}=\sum_{n=1}^{42} I_{\text {total }} \times b_{n \times 1}
$$

Where: $I_{\text {total }}$ represents the total investment of distribution network project, the value of $n$ is $1-42$, representing 42 national economic departments, which $b_{n \times 1}$ represents the pulling coefficient of investment in construction of distribution network project to each department.

(4) Photovoltaic poverty alleviation benefits. The social benefits of the special investment project of the photovoltaic poverty alleviation distribution network project are measured by the electricity revenue brought by the photovoltaic power station to the poor households, and the social benefits of the photovoltaic poverty alleviation are calculated by considering the key variables such as the regional light resource endowment, the photovoltaic installed capacity and the photovoltaic grid price. As shown in equation (16).

$$
B_{\mathrm{pv}}^{t}=C_{\mathrm{pv}}^{t} \times H_{\mathrm{pv}} \times \eta_{\mathrm{pv}} \times P_{\mathrm{pv}}
$$

Where: $C_{\mathrm{pv}}$ represents the installed capacity of the photovoltaic poverty alleviation project, $H_{\mathrm{pv}}$ represents the annual average sunshine time of the area, and $\eta_{\mathrm{pv}}$ represents the system efficiency of the photovoltaic power station, which is generally $78 \% \sim 82 \%$, and ${ }^{P_{\mathrm{pv}}}$ represents the grid price of photovoltaic power generation.

\section{Empirical analysis}

$\mathrm{X}$ distribution network project is located in $\mathrm{Z}$ power supply unit of A+ power supply area in Y City. In order to meet the power supply demand of new load in the area, it is planned to build two 63MVA transformers and $2 \mathrm{~km}$ cable lines, with a total investment of 68.26 million yuan.

\section{1 calculation of economic benefits}

(1) Load forecasting

The annual load forecast results of $\mathrm{Z}$ power supply unit are shown in Table 1.

Table1. Annual load forecast of $Z$ power supply unit

\begin{tabular}{cccc}
\hline Year & $\begin{array}{c}\text { Load forecasting } \\
(\mathrm{MW})\end{array}$ & Year & $\begin{array}{c}\text { Load forecasting } \\
(\mathrm{MW})\end{array}$ \\
\hline 2020 & 36.20 & 2030 & 102.80 \\
2021 & 42.89 & 2031 & 106.92 \\
2022 & 50.81 & 2032 & 111.19 \\
2023 & 60.20 & 2033 & 115.64 \\
2024 & 71.32 & 2034 & 120.27 \\
2025 & 84.50 & 2035 & 120.27 \\
2026 & 87.88 & 2036 & 120.27 \\
2027 & 91.39 & 2037 & 120.27 \\
2028 & 95.05 & 2038 & 120.27 \\
2029 & 98.85 & 2039 & 120.27 \\
\hline
\end{tabular}

(2) Income measurement

The stock load of $\mathrm{Z}$ power supply unit in 2019 is 23.7MW, which is used to calculate the increased load of each year. According to the load density prediction results, the proportion of residents is $47.7 \%$, and that of general industrial and commercial users is $52.3 \%$.

Based on the sales price of 0.4486 yuan $/ \mathrm{kWh}$ for residents and 0.724 yuan/kWh for general industry and commerce in $\mathrm{Y}$ City, the income of additional power supply of $Z$ power supply unit is calculated. The original value of fixed assets of $X$ high-voltage distribution network project accounts for $10 \%$ of the total assets of $Z$ power supply unit. Based on this, the income of $X$ project is calculated.

(3) Cost measurement

The life cycle cost of project $\mathrm{X}$ includes investment cost, power purchase cost and operation and maintenance cost, among which operation and maintenance cost is simplified to $1 \%$ of the total investment of distribution network project. The power purchase cost takes $2.99 \%$ of line loss rate into consideration, and the power purchase is 1.031 times of the sales power.

(4) Economic benefit calculation

The total economic benefit is 58.03 million yuan, the internal rate of return is $12.53 \%$, and the payback period is 8.58 years.

\section{2 calculation of social benefits}

(1) Reliability benefit

After project $\mathrm{X}$ is put into operation, the power supply reliability of power supply unit $\mathrm{Z}$ is increased from $99.9738 \%$ to $99.9886 \%$. Based on the GDP per unit of electricity in Y City of 10.42 yuan/kWh, the reliability benefit of project $\mathrm{X}$ is 17.3731 million yuan.

(2) Environmental benefits

Energy saving and emission reduction electricity of project $\mathrm{X}$ includes saved line loss electricity, photovoltaic power generation and coal to electricity replacement 
electricity. The carbon dioxide, sulfur dioxide and nitrogen oxide emissions reduced due to energy conservation and emission reduction are calculated based on coal-fired power units, with emission coefficients of $750 \mathrm{~g} / \mathrm{kWh}, 0.45 \mathrm{~g} / \mathrm{kWh}$ and $0.35 \mathrm{~g} / \mathrm{kWh}$ respectively, and unit treatment costs of 25 yuan/ton, 1083.8 yuan/ton and 3114.9 yuan/ton respectively. Therefore, the environmental benefit of unit energy conservation and emission reduction is 20.33 yuan/MWh, and that of project $\mathrm{X}$ is 28.2059 million yuan.

(3) Promote economic benefits

According to the complete consumption coefficient of 42 national economic sectors in the 2017 input-output table of the National Bureau of statistics, the investment driving coefficient of the distribution network project to each sector is obtained according to the matrix calculation, and the total driving coefficient is 2.356 , so the industrial driving benefit of project $\mathrm{X}$ investment is 160.82 million yuan.

(4) Benefit calculation of investment promotion

Under the saturated load, the general industrial and commercial power consumption is 276.92GWh. According to the power consumption of $0.06697 \mathrm{kWh} /$ yuan and the pull coefficient of $3 \%$, the investment promotion benefit of project $\mathrm{X}$ is 124.049 million yuan.

Considering the reliability benefit, environmental benefit, industry driving benefit and investment attraction benefit, the social benefit of project $\mathrm{X}$ in the whole life cycle is 330.6013 million yuan.

\section{3 sensitivity analysis}

(1) Sensitivity analysis of economic benefit

The annual load forecasting results, sales price data and line loss rate data are analyzed respectively $\pm 5 \%$ and $\pm 10 \%$ adjustment, the influence degree of three factors on economic benefits is obtained, as shown in Table 2. It is concluded that the most sensitive factor of economic benefit is the selling price and the change of selling price. The range of economic benefit caused by $\pm 10 \%$ is 33.7 million yuan to 82.29 million yuan.

Table2. Sensitivity analysis table of economic benefit

(Unit:Ten thousand yuan)

\begin{tabular}{|c|c|c|c|c|c|}
\hline Change rate of sensitive factors & $-10 \%$ & $-5 \%$ & 0 & $5 \%$ & $10 \%$ \\
\hline Load & 4467 & 5133 & 5803 & 6466 & 7133 \\
\hline Selling price & 3370 & 4585 & 5803 & 7015 & 8229 \\
\hline Line loss rate & 5960 & 5880 & 5803 & 5719 & 5639 \\
\hline
\end{tabular}

(2) Sensitivity analysis of social benefits

The results of load forecasting, energy saving and emission reduction and investment promotion are analyzed respectively $\pm 5 \%$ and $\pm 10 \%$, and the influence degree of three factors on social benefits is obtained, as shown in Table 3. It is concluded that the most sensitive factors of social benefits are the effect of attracting investment and the change of attracting investment. The range of economic benefit caused by $\pm 10 \%$ is 318.05 million yuan to 342.86 million yuan.

Table3. Sensitivity analysis table of social benefit

(Unit:Ten thousand yuan)

\begin{tabular}{|c|c|c|c|c|c|}
\hline $\begin{array}{c}\text { Change rate of sensitive } \\
\text { factors }\end{array}$ & $-10 \%$ & $-5 \%$ & 0 & $5 \%$ & $10 \%$ \\
\hline Load & 32882 & 32971 & 33045 & 33149 & 33238 \\
\hline $\begin{array}{c}\text { Energy saving and } \\
\text { emission reduction }\end{array}$ & 32763 & 32904 & 33045 & 33186 & 33327 \\
\hline $\begin{array}{c}\text { Effect of attracting } \\
\text { investment }\end{array}$ & 31805 & 32425 & 33045 & 33665 & 34286 \\
\hline
\end{tabular}

\section{Conclusion}

This paper proposes a quantitative method of distribution network investment benefit. Compared with the benefit evaluation method based on experience and qualitative index scoring, this method calculates the economic and social benefits of a high-voltage distribution network project investment through the quantitative model based on the data of power supply unit measured by statistics, which avoids the subjectivity of benefit evaluation. It can intuitively see the level of project benefits, facilitate the comparison and selection between projects, and improve the scientificity and objectivity of decision-making. At the same time, this study can improve the capital utilization efficiency and output efficiency of power grid companies.

\section{Acknowledgments}

This work is supported by State Grid Ningxia electric power company science and technology project. (5229NX1908D)

\section{References}

1. ZENG, M., TANG, Y., LIU, H., et al. (2012) Mechanism research of project reserve pool management based on grid investment benefits evaluation. J. East China Electric Power., 40(11): 1877-1881.

2. WANG, G., QIAO K., HOU R., et al. (2017) Evaluation on investment returns of distribution network and optimization of investment projects. J. Proceedings of the CSU-EPSA., 29(12): 146-150.

3. XU, C., GAO, Q., ZHAO, J., et al. (2016) Research on the Full Cycle Evaluation Index System of Social Benefit of Fixed Assets Investment in Power Grid Enterprises. J. Engineering Economy, 26(05): 44-48.

4. GAO, F., WU, J., LIU, D., et al. (2016) Research on the social benefit evaluation method of UHV power grid. J. Power System Protection and Control, 44(22): $12-17$.

5. LIU, Q., CHEN, J. (2012) The Social Benefits Evaluation of Smart Grid in China. J. Ecological Economy, 04:127-129. 
6. LI, M, LIU, W., LI, P., et al. (2020) Method for allocation of county distribution network considering the investment benefit evaluation. J. Journal of Electric Power Science and Technology, 35(06):8389.

7. TIAN, S., CHENG, H., CHANG, H., et al. (2015) Analysis and evaluation of social benefit from UHV power grid. J. Electric Power Automation Equipment, 35(02): 145-153.

8. LIU, S., CAO, Y., FENG, Y., et al. (2015) Research and application of distribution grid investment effectiveness evaluation and decision-making model. J. Power System Protection and Control, 43(2): 119125. 